\title{
Mini-Microabscess Syndrome in Liver Transplant Recipients
}

\author{
Graeme A. MacDonald, ${ }^{1}$ Joel K. Greenson, ${ }^{2}$ Elizabeth A. Delbuono, ${ }^{2}$ William M. Grady, ${ }^{1}$ Robert M. Merion, ${ }^{3}$ \\ Thomas S. Frank, ${ }^{2}$ Michael R. Lucey, ${ }^{1}$ And Henry D. Appelman ${ }^{2}$
}

Cytomegalovirus (CMV) is a significant cause of morbidity in immunosuppressed patients. It is characterized in the liver by parenchymal microabscesses, usually containing CMV-infected cells. However, not all hepatic microabscesses are due to CMV infection. In 1992, we described "mini" microabscess (MMA) syndrome, a distinct clinical syndrome that occurs in transplanted livers. This report analyzes the clinical and laboratory features of 57 cases of MMA syndrome occurring in 52 patients and compares these with 19 biopsy-proven cases of CMV infection. The diagnosis of MMA syndrome can only be made histologically. The microabscesses are smaller and more numerous than in CMV infection, and there are no viral inclusions present. CMV DNA could not be detected in liver biopsy specimens with MMAs by using "nested" polymerase chain reaction (PCR), indicating that MMA syndrome is not caused by CMV infection. The pattern of liver enzyme and bilirubin elevation is predominantly hepatocellular, with transaminase levels elevated, on average, six to eight times the upper limit of normal. The clinical features of MMA syndrome are that it predominantly affects female (40 of 52 patients) orthotopic liver transplant (OLT) recipients of all ages (range, 11 months to 66.9 years). MMA syndrome is unrelated to the indication for initial OLT and tends to occur later after transplantation than CMV infection (median, 91 days postOLT vs. 32 days for CMV hepatitis). Although the etiology of MMA syndrome is not clear, it does not appear to adversely affect graft or patient survival. (HePATOLOGY 1997;26:192197.)

Cytomegalovirus (CMV) infection is a major cause of morbidity in immunosuppressed patients, particularly transplant recipients. ${ }^{1}$ In orthotopic liver transplant (OLT) recipients, CMV infection can result in hepatitis, pneumonitis, chorio-

Abbreviations: CMV, cytomegalovirus; OLT, orthotopic liver transplant; MMA, minimicroabscess; AST, aspartate transaminase; ALT, alanine transaminase; PCR, polymerase chain reaction; $\mathrm{CI}$, confidence interval.

From the Departments of ${ }^{1}$ Internal Medicine, ${ }^{2}$ Pathology, and ${ }^{3}$ Surgery, University of Michigan, Ann Arbor, MI.

Received October 30, 1996; accepted February 28, 1997.

Current addresses: G. A. Macdonald, C.R.C., Royal Brisbane Hospital Research Foundation, Bancroft Center, 300 Herston Rd., Herston, Queensland 4029, Australia; E. A. DelBuono, Department of Pathology, Toledo Hospital, 2142 N. Cove Blvd., Toledo, OH 43606-3899; W. M. Grady, Division of Gastroenterology, Case Western Reserve University, Room 200, 11001 Cedar Rd., Cleveland, OH 44106; T. S. Frank, Medical Director, Myriad Genetic Laboratories, 320 Wakara Way, Salt Lake City, UT 84108; M. R. Lucey, Director of Hepatology, Associate Chief, Division of Gastroenterology, University of Pennsylvania, 3 Dulles, 3400 Spruce St., Philadelphia, PA 19104 6144; other authors remain at the University of Michigan.

Address reprint requests to: G. A. Macdonald, C.R.C., Royal Brisbane Hospital Research Foundation, Bancroft Center, 300 Herston Rd., Herston, Queensland 4029, Australia. Fax: 61-7-3362-0108.

Copyright (C) 1997 by the American Association for the Study of Liver Diseases.

0270-9139/97/2601-0026\$3.00/0 retinitis, duodenal and/or colonic involvement, or disseminated disease..$^{2-4} \mathrm{CMV}$ infection after OLT has been linked to decreased patient survival, particularly in studies published before the availability of CMV-specific antivirals. ${ }^{2,3,5-10}$ Stratta et al. ${ }^{6}$ found that CMV infection in OLT recipients is associated with increases in the duration of the peritransplant hospital stay (38-80 days) and the average costs of these admissions (US\$100,000-250,000).

CMV infection usually occurs in the first 3 months after OLT. ${ }^{2,4,6}$ CMV infection of the liver tends to be focal and may affect hepatocytes, bile duct epithelium, endothelium, or any combination of these sites. Infected cells often contain a single large eosinophilic nuclear inclusion surrounded by a halo, and/or numerous amphophilic granular cytoplasmic inclusions. ${ }^{11}$ In the hepatic lobule, the infected cells are often surrounded by a collection of neutrophils, forming a microabscess. Occasionally a microabscess may lack morphologically infected cells. ${ }^{12}$ In this setting, the presence of microabscesses, even in the absence of typical CMV infected cells, could be interpreted as evidence of CMV infection.

Currently, CMV infection in OLT recipients can usually be successfully treated with ganciclovir., ${ }^{3,6,13}$ Because of the significant costs of untreated CMV infection in OLT recipients, several groups have stressed the need for a high index of suspicion for CMV infection post-OLT and have supported an aggressive approach to the diagnosis and treatment of CMV infection. ${ }^{2,8,13,14}$ However, ganciclovir therapy is expensive in terms of both nursing time and the cost of the drug. Intravenous therapy with ganciclovir also carries the risk of systemic bacterial infection and other complications of intravenous access in this already-compromised population.

In 1992, we described a novel lesion, "mini"-microabscesses (MMAs), seen in 14 liver biopsy specimens from OLT recipients. ${ }^{15}$ When MMAs were first seen, they were considered evidence of CMV infection and treated accordingly. However, as our experience grew, MMAs appeared histologically and clinically distinct from CMV-associated microabscesses. MMAs were smaller and more numerous than CMV-associated microabscesses and were not associated with CMV inclusions. Additionally, they were seen later after liver transplantation than CMV disease. These initial observations led to a review of all liver transplant biopsies at the University of Michigan with microabscesses of any kind. Evidence of CMV involvement was sought by using polymerase chain reaction (PCR) techniques. This paper examines the clinical and histological features of MMA syndrome and the impact of MMA syndrome on patient and graft survival. It also contrasts MMA syndrome with CMV infection in OLT recipients.

\section{PATIENTS AND METHODS}

From February 8, 1985, to April 18, 1995, 511 patients underwent liver transplantation at the University of Michigan Medical 
Center, with 64 of these patients receiving a second OLT, 6 a third, and 3 a fourth transplant. During that time, 2,210 OLT liver biopsies were performed at the University of Michigan. All biopsies with a diagnosis of microabscesses were reviewed by one of the authors (J.K.G.). Nineteen biopsies had clear evidence of CMV infection with CMV inclusion bodies and were used to define the group with $\mathrm{CMV}$ infection. Fifty-seven biopsies revealed multiple microabscesses but no evidence of CMV infection histologically. These 57 patients made up the MMA group and were used to define the histological and clinical features of MMA syndrome.

The histological features studied were the number of neutrophils in each microabscess and the number of microabscesses per square millimeter of biopsy material for the MMA and CMV biopsies. Clinical features reviewed included indication for initial OLT, donor and recipient sex, recipient age, delay from OLT to diagnosis of CMV infection or MMA syndrome, donor and recipient CMV status, and the effect of MMA syndrome on 1- and 5-year graft and patient survival. The effect of CMV infection or MMA syndrome on peak bilirubin, aspartate transaminase (AST), alanine transaminase (ALT), and alkaline phosphatase levels in the 3 days on either side of the date of liver biopsy were reviewed.

Fourteen needle liver biopsy specimens with MMA syndrome, 19 with CMV inclusion bodies present, and 28 with neither CMV infection nor MMA were studied with the PCR for evidence of CMV DNA. PCR was performed on DNA extracted from unstained $5-\mu \mathrm{m}$ tissue sections of formalin-fixed, paraffin-embedded liver biopsy specimens using a technique previously described. ${ }^{16}$ In brief, DNA was extracted by direct boiling of unstained tissue sections that had been deparaffinized in xylene and $100 \%$ ethanol. Positive and negative controls consisted of a paraffin section of cytomegalovirus-infected lung and an empty "mock extraction" tube processed in parallel with patient samples. "Multiplex" amplification was performed in a single reaction for portions of two CMV genes: the major intermediate early gene (CMVMIE), and the late antigen gene (CMV-LA), as well as for human $\beta$ hemoglobin for verification of DNA extraction. The following synthetic oligonucleotide primers were used: 5'-CCACCCGTGGTGCCAGCTCC-3' and 5'-CCCGCTCCTCCTGAGCACCC-3' (CMV-MIE), 5'-AACCTGGTGCCCATGGTGGCTA-3' and 5'-TTTGGGTTGCGCAGCGGGCTG-3' (CMV-LA gene), and 5'-CAGACACCATGGTGC-

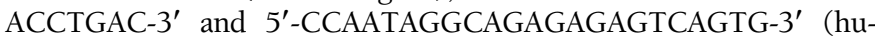
man $\beta$-hemoglobin), resulting in PCR products of 162,132 , and 210 base pairs, respectively. PCR was performed for 35 cycles of $94^{\circ} \mathrm{C}$ for 1 minute, $64^{\circ} \mathrm{C}$ for 2 minutes, and $72^{\circ} \mathrm{C}$ for 2 minutes. Ten percent of the initial PCR reaction was subsequently used as a template for an additional PCR of 35 cycles using the following internally "nested" oligonucleotide primers: 5'-TCTGATTCTCTGGTGTCACC-3' and 5'TCСТCСТCTTCСТCATCACT-3' (CMV-MIE gene), 5'-CGGTTCAGGGTCAGAATCTG-3' and 5'-CCATACGCCTTCCAATTCGG-3' (CMV-LA gene), and 5'-TCCTGAGGAGAAGTCTGCC-3' and $5^{\prime}$-CCTATCAGAAACCCAAGAGTC-3' (human $\beta$-hemoglobin), resulting in PCR products of 120,89 , and 165 base pairs, respectively. Conditions for the second-round PCR were the same as for the first except that an annealing temperature of $54^{\circ} \mathrm{C}$ rather than $64^{\circ} \mathrm{C}$ was used. The resulting PCR product was resolved by electrophoresis through an agarose gel and directly visualized by UV illumination.

The effects of OLT donor and recipient gender were analyzed by $\chi^{2}$ analysis. The time from OLT to diagnosis and the peak bilirubin and liver enzyme levels were compared between MMA patients and those with biopsy-proven CMV infection assuming nonparametric distribution using the Mann-Whitney $U$ test. Statistical analysis of survival was performed with age categorized into quintiles of the frequency distributions (up to 28 years, 29-40, 41-48, 49-56, and 57 or more years of age). Cox proportional hazards survival models were used to estimate 1- and 5-year patient and graft survival rates. Time to diagnosis of MMA was incorporated into these models as a time-dependent covariate, and it was assumed that MMA was not present until the diagnostic biopsy was performed. The proportional-hazards assumption was tested by extending the final models to include interaction terms of gender with $\ln ($ time) and age with
TABLE 1. Indication for Initial Liver Transplantation

\begin{tabular}{lc}
\hline \multicolumn{1}{c}{ Indication for OLT } & $\mathrm{n}^{*}$ \\
\hline Cryptogenic cirrhosis ${ }^{\dagger}$ & 16 \\
Cirrhosis due to ethanol & 7 \\
Fulminant hepatic failure ${ }^{\ddagger}$ & 5 \\
Primary biliary cirrhosis & 5 \\
Primary sclerosing cholangitis & 5 \\
Biliary atresia & 4 \\
Hepatitis C cirrhosis & 4 \\
Autoimmune hepatitis & 2 \\
Chronic hepatitis B cirrhosis & 1 \\
Alagille's syndrome & 1 \\
Wilson's disease & 1 \\
Hepatoblastoma & 1 \\
\hline
\end{tabular}

* Fifty-two patients, with 57 episodes of minimicroabscess syndrome.

$\dagger$ Includes 4 patients who received transplants prior to availability of hepatitis $C$ testing.

₹Includes 4 patients with non-A, non-B fulminant hepatic failure and 1 pregnant woman with HELLP syndrome.

$\ln$ (time). Confidence intervals (95\%) for estimates of survival adjusted for age, sex, and MMA status were estimated using Greenwood's formula. ${ }^{17}$ The study protocol conformed to the ethical guidelines of the 1975 Declaration of Helsinki.

\section{RESULTS}

Fifty-seven separate episodes of minimicroabscess syndrome were documented. These 57 biopsy specimens were taken from 52 patients, with 3 patients having two episodes and 1 patient three episodes of MMA. In those patients with more than one episode of MMA syndrome, there was at least one biopsy that showed no MMA or greater than 6 months with normalization of transaminase levels during the interval separating the episodes of MMA syndrome. Seven of the patients with MMAs had undergone a second OLT, with MMA syndrome occurring after the second OLT in 4 of these 7 patients.

There was a wide variety of primary indications for the initial OLTs in these patients (Table 1), including fulminant hepatic failure, cirrhosis due to ethanol abuse and/or hepatitis $C$ infection, biliary cirrhosis, both primary and secondary, and cryptogenic cirrhosis. Patients with MMAs showed a wide age range, with a median age at the time of first OLT of 40.6 years (range, 11 months to 66.4 years). There was a striking female predominance in patients with MMAs, with 40 of the patients being female and 12 male $(P<.0001)$. Sex of the liver donor was not significantly associated with MMA syndrome (Table 2). Thirty-three of the MMA patients were CMV immunoglobulin $G$ antibody-positive before OLT, whereas 27 of their donors were positive. Nine patients with MMA syndrome had negative pre-OLT CMV serology for both recipient and donor, whereas data were incomplete in a further 2. For patients with CMV, in 16 cases either the donor ( 12 cases) and/or the recipient were CMV IgG positive, whereas data were incomplete for the remaining 3 .

There was a significant difference in the time from OLT to diagnosis of either CMV infection or MMA syndrome. Although there was some overlap, CMV occurred at a median of 32 days post-OLT (range, 5-112 days), whereas MMA syndrome occurred significantly later, at a median of 91 days post-OLT (range, 4-2,816 days, $P=.006$ ). A typical clinical presentation of patients with MMA syndrome was an inciden- 
TABle 2. Relationship Between Sex of OLT Donor and Recipient and Subsequent Diagnosis of MMA Syndrome

\begin{tabular}{lcccccc}
\hline & \multicolumn{2}{c}{ Male Recipient } & & \multicolumn{2}{c}{ Female Recipient } \\
\cline { 2 - 3 } & $\begin{array}{c}\text { Male } \\
\text { Donor }\end{array}$ & $\begin{array}{c}\text { Female } \\
\text { Donor }\end{array}$ & & $\begin{array}{c}\text { Male } \\
\text { Donor }\end{array}$ & $\begin{array}{c}\text { Female } \\
\text { Donor }\end{array}$ & Total \\
\hline MMA present & 11 & 1 & & 28 & 12 & 52 \\
No MMA & 161 & 69 & & 138 & 89 & 457 \\
Total & 172 & 70 & & 166 & 101 & $509 *$
\end{tabular}

NOTE. $P>.50$ using the $\chi^{2}$ test for homogeneity of odds ratio (Woolf method).

* Donor sex was not available for two OLTs.

tal finding of marked elevation of transaminase levels detected through routine blood work before an outpatient OLT clinic visit. For several patients, liver enzyme levels had been measured daily for 1 or more days before liver biopsy. The increase in transaminase levels occurred suddenly, over only 1 or 2 days. These biochemical abnormalities would result in sufficient clinical concern for a liver biopsy to be performed. The elevated transaminase levels would then resolve over several days (Fig. 1). Peak bilirubin concentration was significantly higher in patients with CMV syndrome, with a median peak of $78 \mu \mathrm{mol}$ compared with $26 \mu \mathrm{mol}$ in patients with MMA syndrome $(P=.004$, Table 3$)$. AST and ALT levels were both significantly greater in patients with MMA, with median values of $241 \mathrm{U} / \mathrm{L}$ and $350 \mathrm{U} / \mathrm{L}$, compared with $102 \mathrm{U} / \mathrm{L}$ and $164 \mathrm{U} / \mathrm{L}$ in patients with CMV hepatitis $(P=$ .0001 and .014, respectively). Alkaline phosphatase levels were not significantly different between these two groups.

The initial histological distinctions between MMA syndrome and CMV infection was borne out by reviewing liver biopsy specimens from a larger number of patients. The microabscesses were smaller in MMA syndrome and more numerous than those in CMV infection (Figs. 2 and 3 and Table 4). MMAs were confined to the hepatic lobules, with no involvement of portal tract structures. By definition, no CMV inclusion bodies were found in MMAs.

CMV DNA was not identified in any of the 14 biopsy specimens studied from patients with MMA, despite successful amplification of intact DNA in each of these cases as evidenced by successful amplification of $\beta$-hemoglobin DNA. In contrast, 18 of 19 biopsy specimens with CMV inclusion bodies were positive for DNA by PCR. The one biopsy specimen with CMV inclusions that was negative for CMV DNA by PCR contained only a single CMV inclusion in 17 tissue levels. The failure to amplify CMV DNA from this biopsy was presumably a consequence of a lack of an infected cell in the tissue section used for DNA extraction. In the control group of 28 liver transplant biopsy specimens without CMV

TABLE 3. Peak Bilirubin, AST, ALT, and Alkaline Phosphatase Levels in Patients With MMA Syndrome or CMV Infection in the 3 Days Before to 1 Day After Diagnostic Liver Biopsy

\begin{tabular}{lccl}
\hline & MMA Syndrome & CMV Infection & \multicolumn{1}{c}{$P$} \\
\hline Bilirubin $(\mu \mathrm{mol})$ & $26(5.1-112.2)$ & $78(14-646)$ & .004 \\
AST $(\mathrm{U} / \mathrm{L})$ & $241(38-2481)$ & $102(32-250)$ & .0001 \\
ALT $(\mathrm{U} / \mathrm{L})$ & $320(51-1278)$ & $164(45-617)$ & .014 \\
ALP (U/L) & $279(88-1353)$ & $388(108-1123)$ & .80 \\
\hline
\end{tabular}

NOTE. Data given as median (range).
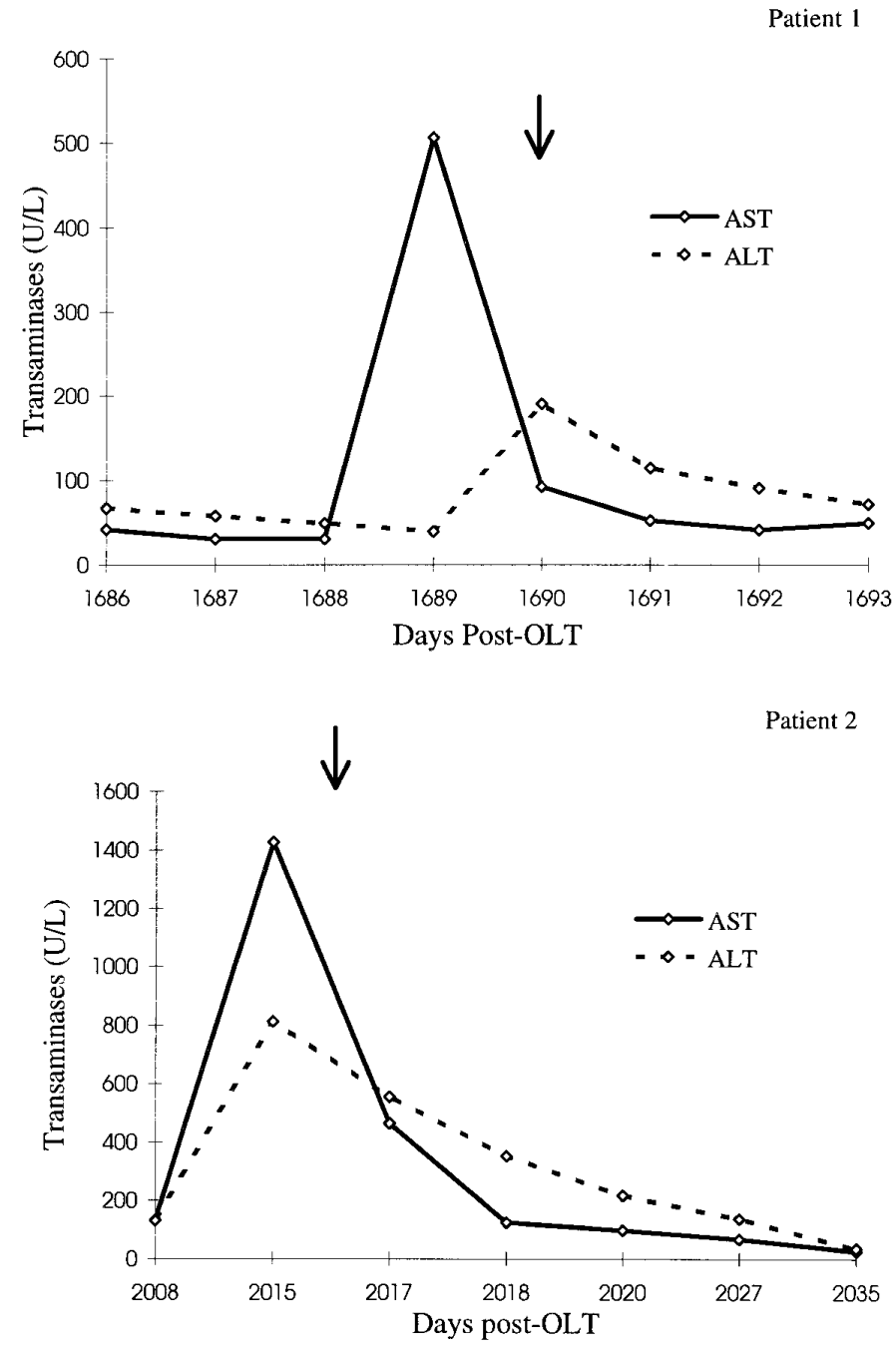

FIG. 1. Time course of AST and ALT concentration changes in 2 patients with MMA syndrome. Arrows indicate the day of biopsy. Patient 1 was a 6-year-old boy who had undergone OLT for biliary atresia approximately 5 years before the episode of MMA syndrome. He had a 1-month history of headache and then sudden onset of fever, lethargy, and nausea coinciding with an abrupt increase in ALT and AST levels. His CMV IgM antibodies were positive and he received ganciclovir intravenously for a total of 4 weeks' postbiopsy. Patient 2 was a 51-year-old woman who had undergone OLT approximately 6 years before this episode of MMA syndrome for a diagnosis of cryptogenic cirrhosis. She was being investigated for chronic diarrhea when it was noted that her ALT and AST levels were elevated. The increase in transaminase levels was not associated with onset of any new symptoms. A liver biopsy showed the typical histological features of MMA syndrome. She did not receive ganciclovir during this, her second episode of MMA syndrome.

inclusions or MMAs, 11 (39\%) were positive for CMV DNA by PCR. The positive and negative controls run in parallel with the tested samples reacted appropriately.

Figure 4 shows Kaplan-Meier plots of the raw data for the effect of MMA syndrome on patient and graft survival in OLT recipients. When the time to diagnosis of MMA was incorporated into the Cox proportional hazard survival model as a time-dependent variable, there was no significant effect on either patient or graft survival (Table 5). The estimated (adjusted for age and sex) 1- and 5-year patient survival rates for all OLT recipients were $74.8 \%$ (95\% confidence interval [CI] 71.0-78.5) and 65.5\% (95\% CI 61.4-69.6), re- 


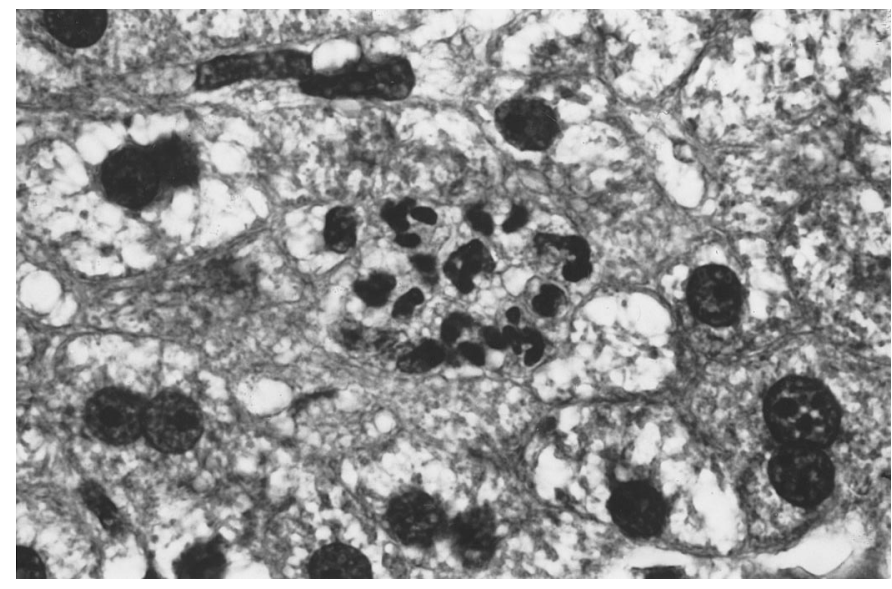

FIG. 2. High-power photomicrograph showing an MMA composed of only a few neutrophils and Kupffer cells. Note the small size of this lesion compared with the CMV-associated microabscess in Fig. 3. (Original magnification $\times 230$.)

spectively, whereas the estimated 1- and 5-year graft survival rates were $66.7 \%$ (95\% CI 62.6-70.8) and 57.2\% (95\% CI 52.9-61.5), respectively. Patient survival was not dependent on recipient age or sex $(P=.74$ and .58 , respectively; Table 5) and graft survival was also not affected by recipient age or sex $(P=.53$ and .32 , respectively). There was little evidence to suggest that the proportional-hazards assumption was violated for patient and graft survival (for patient survival, $P=.71$ across ages and .23 across sexes; for graft survival, $P=.06$ across ages and .10 across sexes).

\section{DISCUSSION}

MMA syndrome is a histologically diagnosed syndrome characterized by numerous, small microabscesses confined to the hepatic lobules. These features serve to distinguish MMA syndrome from CMV infection in which the microabscesses are larger and in which biliary epithelium and endothelial cells are also infected. In addition, CMV inclusion bodies are not found in MMA syndrome, and CMV DNA

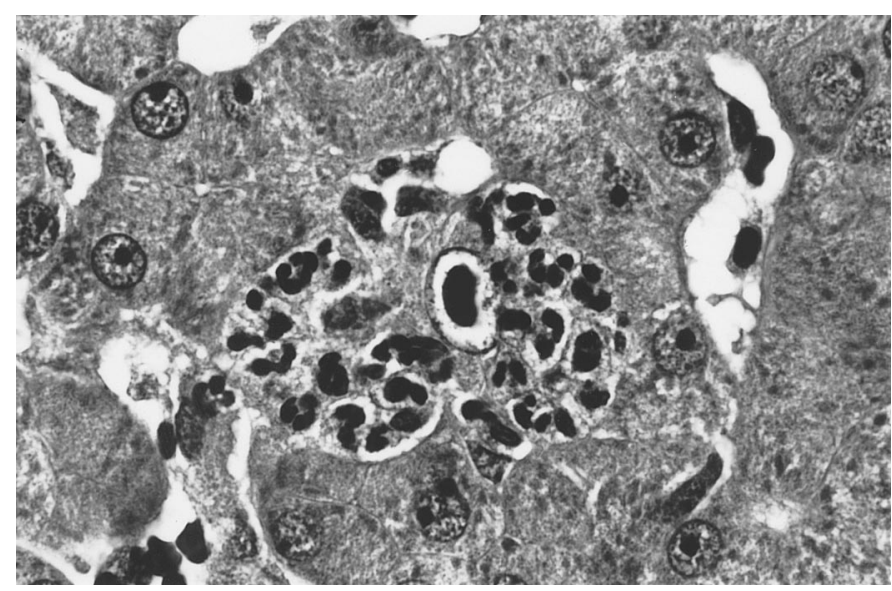

FIG. 3. High-power photomicrograph showing a CMV-infected hepatocyte with characteristic amphophilic nuclear inclusion. The surrounding parenchyma shows a microabscesss composed of numerous $(>20)$ neutrophils.
TABLE 4. Comparison of Histological Features of MMA Syndrome and CMV Infection in Transplanted Livers

\begin{tabular}{lcc}
\hline & MMA Syndrome & CMV Infection \\
\hline Lesions $/ \mathrm{mm}^{2}$ of biopsy & $0.92^{*}$ & 0.049 \\
Neutrophils/lesion & $3-15$ & $10-40$ \\
CMV inclusions or necrotic hepatocyte? & No & Yes \\
\hline
\end{tabular}

$* P<.0001$

could not be detected by nested PCR. The biochemical features that help distinguish MMA syndrome from CMV infection include a greater elevation of AST and ALT levels but a lower peak bilirubin concentration than that observed in CMV infection. However, there is overlap between the two conditions with respect to clinical and biochemical features. MMA syndrome can occur at any time after OLT, whereas CMV hepatitis tends to occur early after OLT. Additionally, MMA syndrome occurred more frequently than CMV hepatitis in our review of OLT liver biopsies. Consequently, we found that MMA syndrome was more likely than CMV hepatitis if microabscesses were present in liver biopsy specimens from patients who were 3 or more months post-OLT. MMA syndrome predominantly affects female OLT recipients but is not related to the indication for first OLT or the age of patients. Importantly, MMA syndrome does not appear to have a negative effect on either patient or graft survival.

The Kaplan-Meier plots (Fig. 4) show an apparent beneficial effect of MMA syndrome on both patient and graft survival. However, MMA syndrome occurs a variable time after OLT (range, 4-2,186 days). Most MMA patients are "selected" from the pool of patients who survive the peri-transplantation period. Thus, the MMA group has relatively little graft or patient loss in the perioperative period; however, the KaplanMeier plots then parallel those for all OLT recipients. This explains, at least in part, the apparent benefit for patient and graft survival in patients with MMA syndrome seen in these plots. Incorporating the time post-OLT to diagnosis of MMA into the proportional-hazards model as a time-dependent variable controls for this potential source of bias. With this modeling, MMA syndrome had no significant effect on patient or graft survival.

The typical presentation of MMA syndrome is of a clinically well female OLT recipient who has recovered from the perioperative OLT period and is attending a routine OLT outpatient appointment. Significant elevation of transaminase levels is detected on pre-outpatient clinic blood work. The elevated transaminase levels result in sufficient concern at the outpatient visit for an urgent liver biopsy to be arranged. This liver biopsy shows the typical histological appearance of MMA syndrome. The liver enzymes return to their usual level over several days.

Early in our experience with minimicroabscess syndrome we were concerned that the MMAs were caused by CMV. As our experience increased it became apparent that the clinical and histological features of MMA syndrome were quite distinct from CMV infection. However, the strongest evidence that CMV infection is not the cause of MMA syndrome comes from the CMV PCR results. CMV DNA could not be detected in any of the 14 MMA biopsy specimens tested, whereas the internal $\beta$-hemoglobin control was amplified in all cases. The technique was able to detect CMV DNA in 18 of 19 biopsy specimens with CMV inclusion bodies present, and was also 
positive in a third of randomly selected OLT liver biopsy specimens. Nested PCR for the detection of CMV DNA from formalin-fixed, paraffin-embedded tissue has been shown to be extremely sensitive, with a negative predictive value of up to $100 \% .^{16,18-20}$ This sensitivity occurs at the expense of specificity and the presence of CMV DNA in a biopsy does not mean there is active CMV infection. However, the failure to detect CMV DNA with this technique is powerful evidence that CMV is not an etiologic factor for MMA syndrome.

Although CMV infection can be excluded as the cause of MMA syndrome, the etiology of MMA syndrome is not clear. There are some epidemiological clues to the etiology of MMA syndrome. The predominance of female OLT recipients in patients with MMA syndrome is interesting, but we have no explanation for it. If MMA syndrome was confined to recipients of a liver from an opposite sex donor then interactions
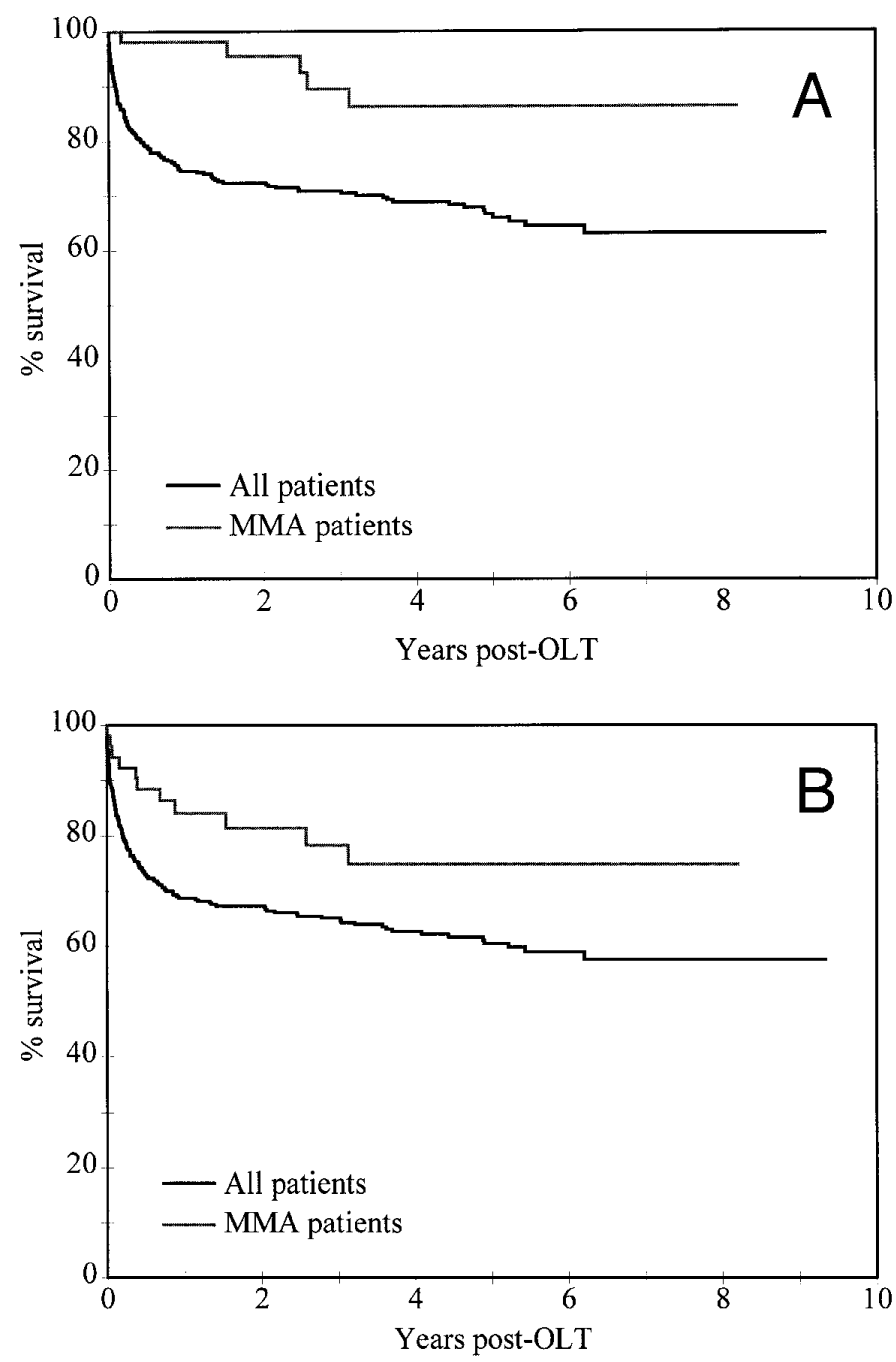

FIG. 4. Kaplan-Meier plots of patient and graft survival rates in all OLT recipients and in patients with MMA syndrome. There is an apparent benefit in the MMA group for both patient and graft survival. This apparent benefit is present, in part, because most patients with MMA syndrome have survived the peritransplant period. Their survival appears better than for all OLT recipients because they are "selected" from the group of patients who have survived the relatively high graft and patient loss that occurs at and shortly after OLT. When the time to onset of MMA syndrome is considered in the proportional-hazards model, there is no significant benefit in terms of graft or patient survival for patients with MMA syndrome.
TABle 5. Hazards Ratios for Patient and Graft Survival by MMA Status, Recipient Sex, and Age

\begin{tabular}{lcc}
\hline & Patient Survival & Graft Survival \\
\hline $\begin{array}{c}\text { MMA status } \\
\text { Absent }\end{array}$ & 1.00 & 1.00 \\
Present & $0.54(0.22-1.33)$ & $0.71(0.33-1.52)$ \\
Sex & 1.00 & 1.00 \\
Male & $1.10(0.78-1.54)$ & $1.17(0.86-1.59)$ \\
Female & 1.00 & 1.00 \\
Age group (yr) & $0.73(0.43-1.23)$ & $0.71(0.44-1.14)$ \\
$\leq 28$ & $0.93(0.57-1.53)$ & $0.89(0.57-1.38)$ \\
$29-40$ & $0.88(0.52-1.47)$ & $0.80(0.50-1.28)$ \\
$41-48$ & $0.81(0.48-1.36)$ & $0.70(0.44-1.12)$ \\
$49-56$ & & \\
$\geq 57$ & & \\
\end{tabular}

NOTE. Data given as mutually adjusted estimates and 95\% CI.

between circulating sex hormones and sex hormone receptors could be responsible. However, MMAs were also detected in patients who received a liver from a same-sex donor. MMA syndrome is not related to the indication for first OLT, and therefore does not appear to be due to a recurrence of the disease that resulted in OLT. Additionally, MMA syndrome is usually diagnosed 2 or more months after OLT, when most patients have recovered from the surgery. This implies MMA syndrome is not a consequence of the transplantation surgery. Finally, MMAs are not age specific and have been detected in liver biopsy specimens from pediatric and adult OLT recipients.

Viral agents other than CMV implicated in viral hepatitis post-OLT include herpes simplex, Epstein-Barr virus, and adenovirus. ${ }^{21-26}$ Histologically, herpes simplex-associated hepatitis has areas of coagulative necrosis not confined to the hepatic lobule, and occasional hepatocytes at the edge of the necrotic foci contain nuclear inclusions. ${ }^{21,24}$ Epstein-Barr virus infection has a variable appearance that ranges from a sinusoidal lymphocytosis, to a monomorphic immunoblastic lymphoma-like infiltrate of liver parenchyma. ${ }^{21}$ These appearances are characteristic and sufficient to discriminate these infections from MMAs.

Microabscess formation can occur with adenovirus-associated hepatitis. ${ }^{23,26}$ However, areas of coagulative necrosis similar to, but smaller than, those observed in herpes simplex-associated hepatitis are described in adenovirus-associated hepatitis, and intranuclear inclusion bodies are typically present. $^{21,23-25}$ Additionally, adenovirus-associated microabscesses are larger than those found in CMV infection, distinguishing it from MMA syndrome. ${ }^{21,23}$ Adenoviral hepatitis has predominantly been reported in pediatric OLT recipients, particularly in the first 3 months after OLT, and up to $45 \%$ of pediatric OLT recipients with invasive adenoviral infection die. ${ }^{21-24,26}$ For these reasons, adenoviral hepatitis in OLT recipients appears histologically and clinically distinct from MMA syndrome.

In summary, MMA syndrome in OLT recipients is a histological diagnosis that is based on a finding of numerous MMAs confined to the hepatic lobules in the absence of inclusions. Although the clinical picture can be suggestive, it is not possible to distinguish MMA syndrome from other causes of abnormal liver enzyme levels without performing a liver biopsy. The etiology of MMAs is unclear but does not appear to be caused by CMV, herpes simplex, or adenovirus 
infection. MMA syndrome predominantly affects female OLT recipients and is unrelated to patient age or to the indication for initial OLT. MMA syndrome appears to have minimal clinical consequences in terms of patient or graft survival. Because many patients feel well at the time transaminase levels are elevated, it is possible that MMA syndrome is even more common than we have found.

Acknowledgment: The authors thank Douglas Armstrong for assistance with patient chart review and data retrieval and Jim Dean and the Organ Transplantation Information Service at the University of Michigan for assistance with retrieving clinical details. Diana Battistutta and Medical Biostatistics Pty. Ltd., Queensland, Australia, provided assistance with patient and graft survival calculations and also kindly reviewed the remainder of the statistical analyses in the manuscript.

\section{REFERENCES}

1. Hirsch M. Herpes group virus infections in the immunocompromised host. In: Rubin R, Young L, eds. Clinical approach to infection in the immunocompromised host. 2nd ed. New York, NY: Plenum, 1988:356366.

2. Hadley S, Samore MH, Lewis WD, Jenkins RL, Karchmer AW, Hammer S. Major infectious complications after orthotopic liver transplantation and comparison of outcomes in patients receiving cyclosporine or FK506 as primary immunosuppression. Transplantation 1995;59:851859

3. Stratta RJ, Shaeffer MS, Markin RS, Wood RP, Langnas AN, Reed EC, Donovan JP, et al. Cytomegalovirus infection and disease after liver transplantation: an overview. Dig Dis Sci 1992;37:673-688.

4. Paya CV, Hermans PE, Washington JA, 2d, Smith TF, Anhalt JP, Wiesner RH, Krom RA. Incidence, distribution, and outcome of episodes of infection in 100 orthotopic liver transplantations. Mayo Clin Proc 1989; 64:555-564.

5. King SM, Petric M, Superina R, Graham N, Roberts EA. Cytomegalovirus infections in pediatric liver transplantation. Am J Dis Child 1990; 144:1307-1310.

6. Stratta RJ, Shaefer MS, Markin RS, Wood RP, Kennedy EM, Langnas A, Reed EC, et al. Clinical patterns of cytomegalovirus disease after liver transplantation. Arch Surg 1989;124:1443144-9.

7. Singh N, Dummer JS, Kusne S, Breinig MK, Armstrong JA, Makowka L, Starzl TE, et al. Infections with cytomegalovirus and other herpesviruses in 121 liver transplant recipients: transmission by donated organ and the effect of OKT3 antibodies. J Infect Dis 1988;158:124-1231.

8. Mellon A, Shepherd RW, Faoagali JL, Balderson G, Ong TH, Patrick M, Cleghorn GJ, et al. Cytomegalovirus infection after liver transplantation in children. J Gastroenterol Hepatol 1993;8:540-544.
9. Candinas D, Gunson BK, Nightingale P, Hubscher S, McMaster P, Neuberger JM. Sex mismatch as a risk factor for chronic rejection of liver allografts. Lancet 1995;346:1117-1121.

10. Paya CV, Hermans PE, Wiesner RH, Ludwig J, Smith TF, Rakela J, Krom RA. Cytomegalovirus hepatitis in liver transplantation: prospective analysis of 93 consecutive orthotopic liver transplantations. J Infect Dis 1989; 160:752-758.

11. Schwartz DA, Wilcox CM. Atypical cytomegalovirus inclusions in gastrointestinal biopsy specimens from patients with the acquired immunodeficiency syndrome: diagnostic role of in situ nucleic acid hybridization. Hum Pathol 1992;23:1019-1026.

12. Snover DC, Hutton S, Balfour HH, Jr., Bloomer JR. Cytomegalovirus infection of the liver in transplant recipients. J Clin Gastroenterol 1987; 9:659-665.

13. Wiesner RH, Marin E, Porayko MK, Steers JL, Krom RA, Paya CV. Advances in the diagnosis, treatment, and prevention of cytomegalovirus infections after liver transplantation. Gastroenterol Clin North Am 1993;22:351-366.

14. Allison AC. Cell-mediated immune responses to virus infections and virus-induced tumours. Br Med Bull 1967;23:60-65.

15. DelBuono E, Frank T, Wilson M, Appelman H. Posttransplant minimicroabscess disease [Abstract]. Mod Pathol 1992;5:96A.

16. Frank TS, Cook SM, DelBuono EA, Wilson MD. A simplified method for detecting cytomegalovirus by polymerase chain reaction from histologic sections of small biopsies. Mod Pathol 1992;5:449-454.

17. Greenwood C. Analysis of survival data. In: Cox DR, Oakes D, eds. Modeling survival data in medical research. London, New York: Chapman and Hall, 1994:56.

18. Brainard JA, Greenson JK, Vesy CJ, Tesi RJ, Papp AC, Snyder PJ, Western L, et al. Detection of cytomegalovirus in liver transplant biopsies. A comparison of light microscopy, immunohistochemistry, duplex PCR and nested PCR. Transplantation 1994;57:1753-1757.

19. DelBuono E, Appelman H, Frank T. Role of polymerase chain reaction in the diagnosis of cytomegalovirus infection in liver transplant patients. Int J Surg Pathol 1995;2:221-226.

20. Schmidt CA, Oettle H, Neuhaus P, Wiens M, Timm H, Wilborn F, Siegert W. Demonstration of cytomegalovirus by polymerase chain reaction after liver transplantation. Transplantation 1993;56:872-874.

21. Demetris AJ. The pathology of liver transplantation. Prog Liver Dis 1990; 9:687-709.

22. Salt A, Sutehall G, Sargaison M, Woodward C, Barnes ND, Calne RY Wreghitt TG. Viral and toxoplasma gondii infections in children after liver transplantation. J Clin Pathol 1990;43:63-67.

23. Koneru B, Jaffe R, Esquivel CO, Kunz R, Todo S, Iwatsuki S, Starzl TE. Adenoviral infections in pediatric liver transplant recipients. JAMA 1987;258:489-492.

24. Demetris AJ, Jaffe R, Starzl TE. A review of adult and pediatric posttransplant liver pathology. Pathol Annu 1987;22:347-386.

25. Cames B, Rahier J, Burtomboy G, de Ville de Goyet J, Reding R, Lamy M, Otte JB, et al. Acute adenovirus hepatitis in liver transplant recipients. J Pediatr 1992; 120:33-37.

26. Michaels MG, Green M, Wald ER, Starzl TE. Adenovirus infection in pediatric liver transplant recipients. J Infect Dis 1992;165:170-174. 